\title{
Determinants of Intention to Use Mobile Phone Caller Tunes to Promote Voluntary Blood Donation: Cross-Sectional Study
}

Bernard Appiah $^{1,2}$, DrPH; James N Burdine ${ }^{3}$, DrPH; Ammar Aftab ${ }^{4}$, BSc (Hons); Lucy Asamoah-Akuoko ${ }^{2,5,6}$, MPH, MD; David A Anum ${ }^{2}$, MBA; Irene A Kretchy ${ }^{7}$ PhD; Elfreda W Samman ${ }^{3}, \mathrm{MPH}$; Patience B Appiah², MPH; Imelda Bates $^{6}, \mathrm{MD}$

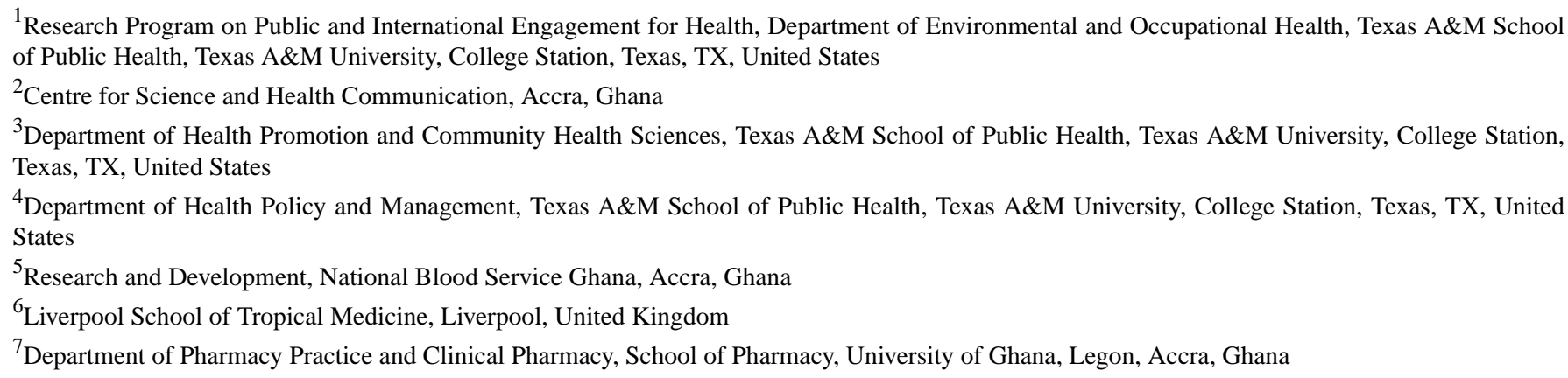

Corresponding Author:

Bernard Appiah, DrPH

Research Program on Public and International Engagement for Health

Department of Environmental and Occupational Health, Texas A\&M School of Public Health

Texas A\&M University

1266 TAMU

College Station, Texas, TX, 77843

United States

Phone: 19794369456

Email:appiah@sph.tamhsc.edu

\section{Abstract}

Background: Voluntary blood donation rates are low in sub-Saharan Africa. Sociobehavioral factors such as a belief that donated blood would be used for performing rituals deter people from donating blood. There is a need for culturally appropriate communication interventions to encourage individuals to donate blood. Health care interventions that use mobile phones have increased in developing countries, although many of them focus on SMS text messaging (short message service, SMS). A unique feature of mobile phones that has so far not been used for aiding blood donation is caller tunes. Caller tunes replace the ringing sound heard by a caller to a mobile phone before the called party answers the call. In African countries such as Ghana, instead of the typical ringing sound, a caller may hear a message or song. Despite the popularity of such caller tunes, there is a lack of empirical studies on their potential use for promoting blood donation.

Objective: The aim of this study was to use the technology acceptance model to explore the influence of the factors-perceived ease of use, perceived usefulness, attitude, and free of cost—on intentions of blood or nonblood donors to download blood donation-themed caller tunes to promote blood donation, if available.

Methods: A total of 478 blood donors and 477 nonblood donors were purposively sampled for an interviewer-administered questionnaire survey at blood donation sites in Accra, Ghana. Data were analyzed using descriptive statistics, exploratory factor analysis, and confirmatory factory analysis or structural equation modeling, leading to hypothesis testing to examine factors that determine intention to use caller tunes for blood donation among blood or nonblood donors who use or do not use mobile phone caller tunes.

Results: Perceived usefulness had a significant effect on intention to use caller tunes among blood donors with caller tunes (beta=.293, $P<.001$ ), blood donors without caller tunes (beta=.165, $P=.02$, nonblood donors with caller tunes (beta=.278, $P<.001$ ), and nonblood donors without caller tunes (beta=.164, $P=.01$ ). Attitudes had significant effect on intention to use caller tunes among blood donors without caller tunes (beta=.351, $P<.001$ ), nonblood donors with caller tunes (beta=.384, $P<.001$ ), nonblood 
donors without caller tunes (beta $=.539, P<.001$ ) but not among blood donors with caller tunes (beta=.056, $P=.44$ ). The effect of free-of-cost caller tunes on the intention to use for blood donation was statistically significant (beta=.169, $P<.001$ ) only in the case of nonblood donors without caller tunes, whereas this path was statistically not significant in other models.

Conclusions: Our results provide empirical evidence for designing caller tunes to promote blood donation in Ghana. The study found that making caller tunes free is particularly relevant for nonblood donors with no caller tunes.

(JMIR Mhealth Uhealth 2018;6(5):e117) doi: 10.2196/mhealth.9752

\section{KEYWORDS}

caller tunes; blood donation; sub-Saharan Africa; technology acceptance model; mobile health

\section{Introduction}

\section{Background}

Lack of adequate blood for transfusions is a major global health challenge in low- and middle-income countries, particularly those in sub-Saharan Africa [1,2]. According to the World Health Organization (WHO), countries need to achieve blood donation rates of at least 1 per 100 population [3]. However, of 67 countries worldwide that fall below this target, 38 are in the WHO Africa region [3]. Lack of adequate blood donation in sub-Saharan Africa has been attributed partly to sociocultural beliefs [4-7]. One such belief is that donated blood would be used for performing rituals [8]. These beliefs could be addressed through use of culturally appropriate communication interventions, including the use of face-to-face communication [9-12], mass media [11-16], and mobile phones [10,11,16,17].

According to a 2015 Pew Research Center report, mobile phone ownership has surged in sub-Saharan Africa, with, for example, Ghana and Kenya, respectively, having $83 \%$ and $82 \%$ of the population owning mobile phones in 2014, up from the 2002 figure of nearly $10 \%$ for both countries [18]. The report shows that across seven African countries surveyed, $80 \%$ use mobile phones to send SMS text messages (short message service, SMS), but only $14 \%$ and $18 \%$ get consumer and health information, respectively, through their mobile phones.

Health care interventions that use mobile phones have increased in developing countries [19], although many of them focus on SMS text messages. The use of mobile phone apps for encouraging voluntary blood donation is increasing in the Western countries, but less so in sub-Saharan Africa [20].

In sub-Saharan Africa, some blood transfusion services have used mobile phone SMS text messages to increase awareness about blood donation [17,21]. Although SMS text messages have an important role to play in health care, they do not reach audiences with limited ability to read or write [22]. Thus, there is a need for culturally appropriate mobile health (mHealth) interventions, including use of voice messages created in languages spoken by the target audience.

\section{Mobile Phone Caller Tunes as New Communication Phenomenon}

One popular phenomenon in sub-Saharan Africa is mobile phone caller tunes. A caller tune is the sound a caller to a mobile phone hears before the receiver picks the call [23]. Normally, one hears the "ring, ring, ring" sound. However, in some sub-Saharan
African countries, a caller to a mobile phone could hear a song or message in place of the "ring, ring, ring" sound.

Caller tunes operate with a logic reverse to that of ring tones. A ring tone is the sound the called party hears. However, a caller tune, also called ringback tone, is the sound the caller hears [24]. A ring tone is usually available as part of the phone settings. A caller tune, however, is usually determined by the mobile telecommunication operator. The normal "ring, ring ring" sound a caller hears is free. However, mobile phone subscribers who download particular songs or messages as caller tunes may pay a relatively small monthly fee to their mobile phone telecommunication companies [25]. Worldwide, many telecommunication companies have caller tunes. For example, in the United States, T-Mobile has caller tunes. Telecommunication companies such as MTN, Vodafone, and Airtel that operate in Africa and Asia also have caller tunes.

Despite the popularity of such caller tunes, there is lack of empirical studies on its potential use for promoting health or improving health care services.

\section{Context: Blood Donation Recruitment Strategies in Ghana}

In Ghana, blood donor recruitment strategies include visiting schools, workplaces, and places of worship such as churches and mosques to collect blood. During school recesses, blood collection teams struggle to get enough voluntary blood donors [26]. Thus, hospitals have to rely on "family" blood donors. Such blood donors may include others who donate blood for money, but present themselves as family members.

There is a need to attract first time voluntary blood donors and retain them as repeat donors because these are the safest donors. The WHO has a target of requiring all countries to get $100 \%$ of all donated blood from voluntary, unpaid donors by 2020 [27]. Thus, the National Blood Service Ghana has been exploring opportunities to increase voluntary blood donation. In a qualitative study to explore how journalists, clinicians, and blood donors could team up to promote blood donation in Ghana, the potential of using mobile phones caller tunes was identified [11].

The overall goal that this project will contribute to is to assess the feasibility of using mobile phone caller tunes on blood donation, if created, to increase the number of blood donors and those who go on to donate regularly. 


\section{Theoretical Foundation}

We selected technology acceptance model (TAM) for this study partly because of its use in assessing user acceptance of novel mobile technologies, particularly in health care [28]. Additionally, our primary reason to use TAM was because it has been tested widely in information systems research [29], including its extensions to include new variables [30].

Although we could not identify a single study that had used TAM to evaluate intention to adopt caller tunes to promote blood donation, TAM constructs such as perceived ease of use, perceived usefulness, attitudes to technologies, and intention to use technologies is particularly applicable to this study because of their validation in health information system environments [31].

TAM posits that perceived ease of use and perceived usefulness of a mobile technology such as caller tune positively influence the attitudes about the technology, with attitudes positively influencing intention to use the technology [32]. Moreover, both perceived usefulness and intention to use the technology positively influence actual use of the technology (Figure 1). We introduced a factor "free of cost" of downloading caller tunes to the original TAM.

\section{Research Models and Hypotheses}

We adapted TAM and used it in the context of mobile phone caller tunes to predict intentions of blood donors and nonblood donors to download caller tunes to promote blood donation. We tested the TAM (as shown in Figure 1) for blood or nonblood donors who use or do not use caller tunes. We focused on these populations because our aim was to explore whether caller tunes could increase the number of blood donors and those who go on to donate regularly.

We introduced "free of cost" of downloading caller tune as a predictor of intention to use caller tunes as seen in Figure 1. The original TAM did not have this variable. However, cost has been operationalized in a prior TAM study as "affordability" or "device perceived as affordable" [33].

\section{Perceived Ease of Use}

Perceived ease of use was defined by Davis as "the degree to which a person believes that using a particular system would be free of effort" [32]. We adapted this definition to the context of mobile phone caller tunes to mean the extent to which users feel it is easy to download caller tunes onto a mobile phone. In general, the belief that it is easy to use a particular health information technology has an influence on one's intention to use the technology. Many studies have shown that perceived ease of use significantly predicts attitudes to technology [32,34-37] and perceived usefulness of the technology [38-41]. Thus, we test the following hypotheses:

Hypothesis 1: perceived ease of use will have a positive effect on perceived usefulness of caller tunes among blood donors with or without caller tunes.

Hypothesis 2: perceived ease of use will have a positive effect on attitudes to caller tunes among nonblood donors with or without caller tunes.

\section{Perceived Usefulness}

Defined by Davis as "the degree to which a person believes that using a particular system would enhance his or her job performance" [32], perceived usefulness is known to have positive effect on attitudes. We adapted this definition to indicate the extent to which users believe caller tunes could help encourage callers to mobile phones to become blood donors, and thus, increase voluntary blood donation. The belief that a given technology is useful could make people develop attitudes to using it and increase their intention to use it. For example, studies show significant relationship between perceived usefulness and attitudes to a health information $[31,40,41]$ and intention to use technology $[31,33,38,42]$.

Thus, based on these results, our third and fourth hypotheses are as follows:

Hypothesis 3: perceived usefulness will have a positive effect on attitudes to caller tunes among blood donors or nonblood donors with or without caller tunes.

Hypothesis 4: perceived usefulness will have positive effects on intention to use caller tunes among blood donors or nonblood donors with or without caller tunes.

Figure 1. Conceptual research model (technology acceptance model).

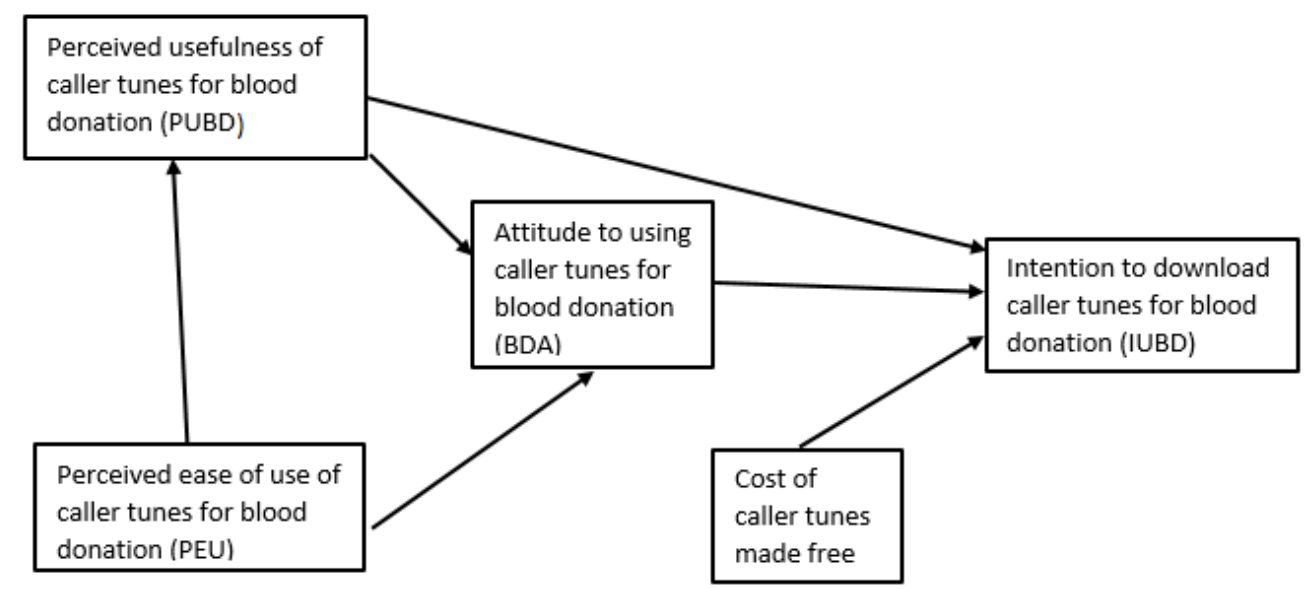




\section{Attitudes}

Attitude was adopted from the theory of reasoned action that posits that intention to perform a given behavior is determined by an individual's overt behavior [43]. Some studies have shown significant relationship between attitudes and behavioral intention [31,40,41]. Thus, this study explores the relationship between attitude and behavioral intention in the context of using mobile phone caller tunes for aiding blood donation.

Hypothesis 5: attitudes toward caller tunes will have positive effects on intention to use caller tunes among blood donors or nonblood donors with or without caller tunes.

\section{Free of Cost}

The cost of a technology could determine whether people intend to use it or will actually use it. For example, affordability has been found to influence patients' intention to use point-of-care medical devices for medical testing [33]. Moreover, cost negatively influences the adoption of mHealth services [44]. Thus, we assessed whether blood donation-themed caller tunes that are to be made free to download could influence the intentions of blood donors and nonblood donors to use them to encourage callers to donate blood.

Hypothesis 6: making caller tunes free to download will have positive effects on intention to download it for promoting blood donation.

\section{Behavioral Intention}

Behavioral intention is a construct that describes people's target or goal to use a future product or service [45]. Studies show significant relationship between intention and actual use [46,47]. Because caller tunes on blood donation have not yet been developed, this study does not assess the relationship between intention and actual use of mobile phone caller tunes for promoting blood donation. Currently, mobile phone caller tunes in Ghana include songs of popular artistes and religious messages. The outcome of this feasibility study would inform the design and use of caller tunes to promote blood donation among blood or nonblood donors.

\section{Methods}

\section{Survey Development}

Two questionnaires, one for blood donors and another for nonblood donors, were adapted from previous studies on TAM conducted outside Ghana (eg, [48-57], see Multimedia Appendix $1)$. The questionnaires were then pretested among 5 blood donors and 5 nonblood donors at the Korle Bu Blood Bank in Accra, Ghana for ease and understanding of use. The pretest resulted in reduced overall number of questionnaire items because some respondents found it time-consuming in answering questions on use of caller tunes for promoting blood donation, medication adherence, and patient reporting of adverse drug reactions (ADRs). Seven-point Likert scale with answers ranging from "strongly agree" (1) to "strongly disagree" (7) was used to measure perceived ease of use, perceived usefulness, attitudes, behavioral intention, and free of cost as presented in Multimedia Appendix 1.

\section{Data Collection}

Blood donors and nonblood donors were recruited for the questionnaire survey at blood donation sites such as schools, churches, hospitals, and workplaces in Accra, Ghana. Purposive sampling [58] was used to recruit blood or nonblood donors because it was practically impossible to have a list of all blood donors or nonblood donors at blood donation sites to be used for random sampling. We were also interested in the perspectives of blood or nonblood donors; hence, the use of purposive sampling.

The inclusion criteria for both blood or nonblood donors were being at least 18 years of age and being able to understand English. In addition, blood donors were selected if they indicated that they have donated blood before, including on the day of the interview. The survey did not identify whether those who indicated that they had donated blood before were unpaid blood donors, paid blood donors, or irregular blood donors such as those who donate blood for family members or friends.

Each prospective blood donor or nonblood donor who understood English was provided with information about the study verbally. Those who consented to the study were interviewed. Trained interviewers read the questionnaires in English to the participants and recorded participants' responses on the paper-based survey questionnaires, which were designed in English (see Multimedia Appendix 2). On average, each interview lasted about $20 \mathrm{~min}$.

The survey questionnaires required participants to answer questions on TAM constructs related to blood donation and intention to use mobile phone caller tunes to promote blood donation, medication adherence, and patient reporting of ADRs as part of a larger project. The focus of this study is on the blood donation component. Data collection occurred from October 2016 to December 2016.

A total of 955 questionnaires were successfully completed for 478 blood donors and 477 nonblood donors out of the 965 who met the inclusion criteria and were approached, representing $99.0 \%$ response rate. The 10 agreed to participate but did not complete the questionnaires because they had to leave the blood donation sites. Each respondent received Ghana Cedi equivalent of US $\$ 1$ as compensation for the time spent in responding to the questionnaires. The study protocol was approved by ethics committees of the Ghana Health Service (GHS-ERC 05/08/16) and Texas A\&M University (IRB2016-0655D).

Among the 955 participants, 49.2\% (470/955) did not have a mobile phone caller tune, and 50.8\% (485/955) had mobile phone caller tune (see Table 1). 
Table 1. Demographic characteristics of blood or nonblood donors with or without caller tunes.

\begin{tabular}{|c|c|}
\hline Characteristic & Total, $\mathrm{n}(\%)$ \\
\hline \multicolumn{2}{|l|}{ Gender } \\
\hline Male & $633(66.6)$ \\
\hline Female & $317(33.4)$ \\
\hline \multicolumn{2}{|l|}{ Age in years } \\
\hline $18-20$ & $365(38.3)$ \\
\hline $21-30$ & $469(49.2)$ \\
\hline $31-40$ & $85(8.9)$ \\
\hline $41-50$ & $26(2.7)$ \\
\hline $51-60$ & $5(0.5)$ \\
\hline$>60$ & $3(0.3)$ \\
\hline \multicolumn{2}{|l|}{ Blood donation status } \\
\hline Nonblood donor & $477(49.9$ \\
\hline Blood donor & $478(50.1)$ \\
\hline \multicolumn{2}{|l|}{ Mobile phone has caller tune } \\
\hline No & $470(49.2)$ \\
\hline Yes & $485(50.8)$ \\
\hline \multicolumn{2}{|l|}{ Education } \\
\hline Primary & $19(2.0)$ \\
\hline Middle school & $11(1.2)$ \\
\hline Junior high school & $68(7.1)$ \\
\hline Senior high school & $345(36.2)$ \\
\hline Above senior high school & $509(53.5)$ \\
\hline
\end{tabular}

\section{Measurement}

Data from the survey were divided into four subsets based on blood donation status and the use of caller tune, namely blood donors with caller tuners, blood donors who do not use caller tunes, nonblood donors with caller tunes, and nonblood donors who did not have caller tunes. The data from each subset (with sample sizes 200-278) were analyzed using descriptive statistics, exploratory factor analysis, and confirmatory factor analysis or structural equation modeling. Results based on non-normality tests showed that each data for a subgroup was not normally distributed as revealed by significant values for Shapiro-Wilk test statistics and high values of kurtosis.

We used TAM for structural equation modeling analysis with the aid of maximum likelihood estimation routines in IBM SPSS AMOS version 25 (IBM Corp). We selected maximum likelihood estimation approach because it performs reasonably well for non-normal data under analytic conditions such as excessive kurtosis and small sample sizes [59], especially those less than 1000 [60].

There were five measures in the model: perceived usefulness, perceived ease of use, attitude, free of cost, and intention to use. Confirmatory factor analysis was conducted for perceived ease of use (seven items for those with caller tunes and three items for those without caller tunes), attitudes to using caller tunes (four items), and perceived usefulness (three items), but not for free of cost and intention to download caller tunes because each had only one item. Multimedia Appendix 1 outlines all items and their corresponding statements. Single items for measuring intention have been used in previous TAM research [61], especially when the aim was to shorten the survey [62].

\section{Reliability and Validity}

Results based on use of IBM SPSS version 24 (IBM Corp) for descriptive analyses of the constructs showed that composite reliability scores were all well above the 0.7 level threshold, and Cronbach alpha scores were also well above 7 threshold [63] for blood donors with caller tunes (see Table 2), nonblood donors with caller tunes (see Table 3), blood donors with no caller tunes (see Table 4), and nonblood donors with caller tunes (see Table 5). We assessed discriminant validity-the extent to which a given construct is different from the others indicated in the instrument-by using the average variance extracted (AVE), which determines the mean variance shared between a given construct and how it was measured. Discriminant validity is established when the AVE is at least 0.50 [63]. Such a figure shows that the construct indicated at least $50 \%$ of the measurement variance. Tables 2-5 show AVE scores greater than 0.5 and Cronbach alpha values of at least 0.7 , thus suggesting that the instrument used for the study met acceptable validity and reliability levels. 
Table 2. Factor analysis, reliability, and validity of measures for blood donors with caller tunes. Multimedia Appendix 1 outlines all items and their corresponding statements.

\begin{tabular}{|c|c|c|c|c|c|}
\hline \multirow[t]{2}{*}{ Item } & \multicolumn{3}{|l|}{ Internal reliability } & \multicolumn{2}{|l|}{ Convergent validity } \\
\hline & Cronbach alpha & Item-total correlation & Factor loading & $\begin{array}{l}\text { Composite reliabili- } \\
\text { ty }\end{array}$ & Average variance extracted \\
\hline Perceived ease of use (PEU) & .893 & & & 0.92 & 0.61 \\
\hline PEU1 & & 0.63 & 0.72 & & \\
\hline PEU2 & & 0.74 & 0.82 & & \\
\hline PEU3 & & 0.74 & 0.82 & & \\
\hline PEU4 & & 0.67 & 0.76 & & \\
\hline PEU5 & & 0.70 & 0.79 & & \\
\hline PEU6 & & 0.74 & 0.82 & & \\
\hline PEU7 & & 0.64 & 0.74 & & \\
\hline $\begin{array}{l}\text { Perceived usefulness for blood } \\
\text { donation (PUBD) }\end{array}$ & .862 & & & 0.92 & 0.77 \\
\hline PUBD1 & & 0.75 & 0.89 & & \\
\hline PUBD2 & & 0.74 & 0.89 & & \\
\hline PUBD3 & & 0.74 & 0.88 & & \\
\hline $\begin{array}{l}\text { Attitudes to using caller tunes for } \\
\text { blood donation (BDA) }\end{array}$ & .851 & & & 0.90 & 0.70 \\
\hline BDA1 & & 0.74 & 0.87 & & \\
\hline BDA2 & & 0.65 & 0.80 & & \\
\hline BDA3 & & 0.77 & 0.89 & & \\
\hline BDA4 & & 0.63 & 0.79 & & \\
\hline
\end{tabular}

Table 3. Factor analysis, reliability, and validity of measures for blood donors with no caller tunes. Multimedia Appendix 1 outlines all items and their corresponding statements.

\begin{tabular}{|c|c|c|c|c|c|}
\hline \multirow[t]{2}{*}{ Item } & \multicolumn{3}{|l|}{ Internal reliability } & \multicolumn{2}{|l|}{ Convergent validity } \\
\hline & Cronbach alpha & Item-total correlation & Factor loading & $\begin{array}{l}\text { Composite reliabili- } \\
\text { ty }\end{array}$ & Average variance extracted \\
\hline Perceived ease of use (PEU) & .859 & & & 0.92 & 0.78 \\
\hline PEU1 & & 0.76 & 0.90 & & \\
\hline PEU2 & & 0.83 & 0.93 & & \\
\hline PEU3 & & 0.63 & 0.82 & & \\
\hline $\begin{array}{l}\text { Perceived usefulness for blood } \\
\text { donation (PUBD) }\end{array}$ & .811 & & & 0.89 & 0.73 \\
\hline PUBD1 & & 0.61 & 0.82 & & \\
\hline PUBD2 & & 0.76 & 0.90 & & \\
\hline PUBD3 & & 0.63 & 0.84 & & \\
\hline $\begin{array}{l}\text { Attitudes to using caller tunes for } \\
\text { blood donation (BDA) }\end{array}$ & .792 & & & 0.87 & 0.63 \\
\hline BDA1 & & 0.67 & 0.83 & & \\
\hline BDA2 & & 0.56 & 0.76 & & \\
\hline BDA3 & & 0.66 & 0.82 & & \\
\hline BDA4 & & 0.57 & 0.77 & & \\
\hline
\end{tabular}


Table 4. Factor analysis, reliability, and validity of measures for nonblood donors with caller tunes. Multimedia Appendix 1 outlines all items and their corresponding statements.

\begin{tabular}{|c|c|c|c|c|c|}
\hline \multirow[t]{2}{*}{ Item } & \multicolumn{3}{|l|}{ Internal reliability } & \multicolumn{2}{|l|}{ Convergent validity } \\
\hline & Cronbach alpha & Item-total correlation & Factor loading & $\begin{array}{l}\text { Composite reliabili- } \\
\text { ty }\end{array}$ & Average variance extracted \\
\hline Perceived ease of use (PEU) & .84 & & & 0.88 & 0.51 \\
\hline PEU1 & & 0.63 & 0.75 & & \\
\hline PEU2 & & 0.58 & 0.71 & & \\
\hline PEU3 & & 0.58 & 0.71 & & \\
\hline PEU4 & & 0.44 & 0.56 & & \\
\hline PEU5 & & 0.58 & 0.70 & & \\
\hline PEU6 & & 0.65 & 0.77 & & \\
\hline PEU7 & & 0.63 & 0.75 & & \\
\hline $\begin{array}{l}\text { Perceived usefulness for blood } \\
\text { donation (PUBD) }\end{array}$ & .84 & & & 0.90 & 0.75 \\
\hline PUBD1 & & 0.64 & 0.83 & & \\
\hline PUBD2 & & 0.78 & 0.91 & & \\
\hline PUBD3 & & 0.68 & 0.86 & & \\
\hline $\begin{array}{l}\text { Attitudes to using caller tunes for } \\
\text { blood donation (BDA) }\end{array}$ & .82 & & & 0.88 & 0.65 \\
\hline BDA1 & & 0.65 & 0.81 & & \\
\hline BDA2 & & 0.60 & 0.78 & & \\
\hline BDA3 & & 0.65 & 0.81 & & \\
\hline BDA4 & & 0.66 & 0.82 & & \\
\hline
\end{tabular}

Table 5. Factor analysis, reliability, and validity measures for nonblood donors with no caller tunes. Multimedia Appendix 1 outlines all items and their corresponding statements.

\begin{tabular}{|c|c|c|c|c|c|}
\hline \multirow[t]{2}{*}{ Item } & \multicolumn{3}{|l|}{ Internal reliability } & \multicolumn{2}{|l|}{ Convergent validity } \\
\hline & Cronbach alpha & Item-total correlation & Factor loading & $\begin{array}{l}\text { Composite reliabili- } \\
\text { ty }\end{array}$ & Average variance extracted \\
\hline Perceived ease of use (PEU) & .88 & & & 0.93 & 0.81 \\
\hline PEU1 & & 0.78 & 0.91 & & \\
\hline PEU2 & & 0.85 & 0.94 & & \\
\hline PEU3 & & 0.69 & 0.85 & & \\
\hline $\begin{array}{l}\text { Perceived usefulness for blood } \\
\text { donation (PUBD) }\end{array}$ & .90 & & & 0.94 & 0.84 \\
\hline PUBD1 & & 0.72 & 0.86 & & \\
\hline PUBD2 & & 0.89 & 0.95 & & \\
\hline PUBD3 & & 0.83 & 0.93 & & \\
\hline $\begin{array}{l}\text { Attitudes to using caller tunes for } \\
\text { blood donation (BDA) }\end{array}$ & .92 & & & 0.95 & 0.82 \\
\hline BDA1 & & 0.82 & 0.90 & & \\
\hline BDA2 & & 0.85 & 0.92 & & \\
\hline BDA3 & & 0.84 & 0.91 & & \\
\hline BDA4 & & 0.78 & 0.87 & & \\
\hline
\end{tabular}




\section{Results}

\section{Descriptive Analysis}

The means of the constructs as indicated in Table 6 show that respondents had positive views about using mobile phone caller tunes for promoting blood donation given that the 7-point Likert scale ranged from 1 (strongly agree) to 7 (strongly disagree).

\section{Model Fit and Structural Models}

Three of the research models had goodness of fit indices showing good fit to the data as shown in Table 7. Only the model for nonblood donors with caller tunes had values of normed fit index (NFI), comparative fit index (CFI), and incremental fit index (IFI) not meeting recommended levels [64]. The root mean square error of approximation (RMSEA) value for blood donors with no caller tune was 0 and that for nonblood donors with caller tunes was 0.11 , whereas that for blood donors with caller tunes was 0.07 and nonblood donors with no caller tunes was 0.08 (Table 8 ). At $90 \% \mathrm{CI}$, the $P$ values of the RMSEA for all but the model involving nonblood donors with caller tunes were not statistically significant (Table 7). All the models met the recommended values of chi square or degree of freedom ratio [65].

\section{Hypothesis Tests}

Most of the results support the proposed hypotheses (Table 8).

We hypothesized that perceived ease of use will have a positive effect on perceived usefulness of caller tunes. The path coefficient was positive for blood donors or nonblood donors with or without caller tunes and statistically significant for all models except that for blood donors with no caller tunes (see Table 8 and Figures 2-5).

We hypothesized that perceived ease of use will have a positive effect on attitudes to caller tunes. All the path coefficients were positive. However, other than nonblood donors with no caller tunes, which was statistically significant $(P=.001$; see Figure 5,Table 8), all the other models had statistically nonsignificant relationship between perceived ease of use and perceived usefulness of caller tunes.

We hypothesized that perceived usefulness will have a positive effect on attitudes to caller tunes. The findings show that all the models supported this hypothesis.

Table 6. Means and SDs of the constructs for blood or nonblood donors with or without caller tunes.

\begin{tabular}{lllll}
\hline Construct & $\begin{array}{l}\text { Blood donors with caller } \\
\text { tunes }(\mathrm{N}=278), \text { mean }(\mathrm{SD})\end{array}$ & $\begin{array}{l}\text { Blood donors with no caller } \\
\text { tunes }(\mathrm{N}=200), \text { mean }(\mathrm{SD})\end{array}$ & $\begin{array}{l}\text { Nonblood donors with caller } \\
\text { tunes }(\mathrm{N}=208), \text { mean }(\mathrm{SD})\end{array}$ & $\begin{array}{l}\text { Nonblood donors with no caller } \\
\text { tunes }(\mathrm{N}=270), \text { mean }(\mathrm{SD})\end{array}$ \\
\hline $\begin{array}{l}\text { Intention to use caller } \\
\text { tunes for promoting } \\
\text { blood donation }\end{array}$ & $1.08(0.27)$ & $1.15(0.35)$ & $1.86(1.05)$ & $2.07(1.13)$ \\
$\begin{array}{l}\text { Perceived ease of use } \\
\text { caller tunes for promot- } \\
\text { ing blood donation }\end{array}$ & $1.97(1.05)$ & $2.19(0.61)$ & $1.90(0.75)$ & $2.05(1.15)$ \\
$\begin{array}{l}\text { Perceived usefulness for } \\
\text { blood donation }\end{array}$ & $1.87(0.95)$ & $1.90(0.81)$ & $2.23(1.06)$ & $2.15(1.13)$ \\
$\begin{array}{l}\text { Attitudes to using caller } \\
\text { tunes for blood donation }\end{array}$ & $1.66(0.68)$ & $1.73(0.66)$ & $1.87(0.67)$ & $1.90(0.92)$ \\
\begin{tabular}{l} 
Free of cost \\
\hline
\end{tabular} & $2.88(2.17)$ & $2.90(2.29)$ & $2.34(1.67)$ & $2.53(1.88)$ \\
\hline
\end{tabular}

Table 7. Model fit indices for blood or nonblood donors with or without caller tunes.

\begin{tabular}{|c|c|c|c|c|c|c|}
\hline Model or Fit Index & $\begin{array}{l}\text { Blood donors with } \\
\text { caller tunes }(\mathrm{n}=278)\end{array}$ & $\begin{array}{l}\text { Blood donors with no } \\
\text { caller tunes }(n=200)\end{array}$ & $\begin{array}{l}\text { Nonblood donors with } \\
\text { caller tunes }(n=208)\end{array}$ & $\begin{array}{l}\text { Nonblood donors with } \\
\text { no caller tunes }(\mathrm{n}=270)\end{array}$ & $\begin{array}{l}\text { Recommended } \\
\text { value }\end{array}$ & Reference \\
\hline $\mathrm{NFI}^{\mathrm{a}}$ & 0.95 & 0.97 & 0.92 & 0.97 & $\geq 0.95$ & 64 \\
\hline $\mathrm{IFI}^{\mathrm{b}}$ & 0.97 & 1.02 & 0.94 & 0.94 & $\geq 0.95$ & 64 \\
\hline Tucker-Lewis index & 0.90 & 1.07 & 0.78 & 0.96 & $\geq 0.95$ & 64 \\
\hline $\mathrm{CFI}^{\mathrm{c}}$ & 0.97 & 1.00 & 0.94 & 0.98 & $\geq 0.95$ & 64 \\
\hline $\begin{array}{l}\mathrm{RMSEA}^{\mathrm{d}}(90 \% \mathrm{CI} \\
P \text { value })\end{array}$ & $0.07(0.00-0.13 ; .24)$ & $0(0.00-0.09 ; .80)$ & $0.11(0.05-0.18 ; .046)$ & $0.08(0.03-0.14 ; .12)$ & $<0.06$ & 64 \\
\hline $\begin{array}{l}\text { Chi square or degree } \\
\text { of freedom ratio }\end{array}$ & 2.3 & 0.6 & 3.5 & 2.9 & $<5.00$ & 65 \\
\hline
\end{tabular}

${ }^{\mathrm{a} N F I}$ : normed fit index.

${ }^{b}$ IFI: incremental fit index.

${ }^{\mathrm{c}} \mathrm{CFI}$ : comparative fit index.

${ }^{\mathrm{d}}$ RMSEA: root mean square error of approximation. 
Table 8. Path models for blood or nonblood donors with or without caller tunes.

\begin{tabular}{|c|c|c|c|c|c|c|c|c|c|c|c|c|}
\hline \multirow{2}{*}{$\begin{array}{l}\text { Type of participant } \\
\text { Causal path }\end{array}$} & \multicolumn{3}{|c|}{$\begin{array}{l}\text { Blood donors with caller tunes } \\
(n=278)\end{array}$} & \multicolumn{3}{|c|}{$\begin{array}{l}\text { Blood donors with no caller } \\
\text { tunes }(n=200)\end{array}$} & \multicolumn{3}{|c|}{$\begin{array}{l}\text { Nonblood donors with caller } \\
\text { tunes }(n=208)\end{array}$} & \multicolumn{3}{|c|}{$\begin{array}{l}\text { Nonblood donors with no } \\
\text { caller tunes }(n=270)\end{array}$} \\
\hline & Estimate & SE & $P$ value & Estimate & SE & $P$ value & Estimate & SE & $P$ value & Estimate & SE & $P$ value \\
\hline $\mathrm{PUBD}^{\mathrm{a}} \leftarrow \mathrm{PEU}^{\mathrm{b}}$ & 0.27 & 0.05 & $<.001$ & 0.06 & 0.09 & .41 & 0.30 & 0.09 & $<.001$ & 0.41 & 0.06 & $<.001$ \\
\hline $\mathrm{BDA}^{\mathrm{c}} \leftarrow \mathrm{PUBD}$ & 0.60 & 0.04 & $<.001$ & 0.46 & 0.05 & $<.001$ & 0.50 & 0.04 & $<.001$ & 0.64 & 0.04 & $<.001$ \\
\hline $\mathrm{BDA} \leftarrow \mathrm{PEU}$ & 0.08 & 0.03 & .09 & -0.04 & 0.07 & .48 & 0.03 & 0.06 & .70 & 0.19 & 0.04 & $<.001$ \\
\hline $\mathrm{IUBD}^{\mathrm{d}} \leftarrow \mathrm{PUBD}$ & 0.293 & 0.02 & $<.001$ & 0.165 & 0.031 & .02 & 0.278 & 0.064 & $<.001$ & 0.164 & 0.063 & .01 \\
\hline $\mathrm{IUBD} \leftarrow \mathrm{BDA}$ & 0.056 & 0.028 & .44 & 0.351 & 0.038 & $<.001$ & 0.384 & 0.101 & $<.001$ & 0.539 & 0.077 & $<.001$ \\
\hline $\mathrm{IUBD} \leftarrow \mathrm{CFDBD} 1^{\mathrm{e}}$ & -0.049 & 0.007 & .39 & -0.089 & 0.01 & .16 & 0.104 & 0.035 & .067 & 0.169 & 0.026 & $<.001$ \\
\hline
\end{tabular}

${ }^{\text {a} P U B D: ~ p e r c e i v e d ~ u s e f u l n e s s ~ f o r ~ b l o o d ~ d o n a t i o n . ~}$

${ }^{\mathrm{b}} \mathrm{PEU}$ : perceived ease of use caller tunes for promoting blood donation.

${ }^{c}$ BDA refers to attitudes to using caller tunes for blood donation.

dIUBD: intention to use caller tunes for promoting blood donation.

${ }^{\mathrm{e}} \mathrm{CFDBD} 1$ implies free of cost.

Our hypothesis that perceived usefulness will have positive effects on intention to use caller tunes among blood donors with or without caller tunes was supported for all the path models (Table 8). Perceived usefulness had significant effect on intention to use caller tunes among blood donors with caller tunes (beta $=.293, P<.001$ ), blood donors without caller tunes (beta=.165, $P=.019$ ), nonblood donors with caller tunes (beta $=.278, P<.001$ ), and nonblood donors without caller tunes (beta=.164, $P=.01$ ).

Our hypothesis was that attitude will have positive effects on intention to use caller tunes among blood donors or nonblood donors with or without caller tunes. Attitudes had significant effect on intention to use caller tunes among blood donors without caller tunes (beta $=.351, P<.001$ ), nonblood donors with caller tunes (beta $=.384, P<.001$ ), nonblood donors without caller tunes (beta=.539, $P<.001$ ), but a statistically nonsignificant effect with blood donors with caller tunes (beta=.056, $P=.44$ ).

We hypothesized that making caller tunes free to download will have positive effects on intention to use caller tunes among blood donors or nonblood donors with or without caller tunes. The effect of free of cost caller tunes on the intention to download and use for blood donation was statistically significant (beta=.169, $P<.001$ ) only in the case of nonblood donors without caller tunes (Figure 5), whereas this path was statistically not significant in the models for blood donors with caller tunes (Figure 2) and without caller tunes (Figure 4), as well as nonblood donors with caller tunes (Figure 3 ).

Perceived usefulness and attitudes to caller tunes explained $10.7 \%$ of the variance in intention to use caller tunes for blood donation among blood donors with caller tunes, with the variance in intention increasing slightly to $11.2 \%$ when free to download was added to the model (Table 9).
Among blood donors with no caller tunes, perceived usefulness, attitudes to using caller tunes for blood donation, and free of cost explained $21.1 \%$ of the variance in intention. Without free of cost, the variance in intention was $19.7 \%$. The greatest variance in intention was obtained among nonblood donors, with perceived usefulness, attitudes, and free of cost explaining $34.4 \%$ and $47.4 \%$ of the variances in intention to use caller tunes among those with caller tunes and those without caller tunes, respectively.

Free of cost reduced the variance in intention to download and use caller tunes for blood donation only in the case of nonblood donors with caller tunes (from $34.7 \%-34.4 \%$ ), while slightly increasing the variances in intention for blood donors with caller tunes (from 10.7\%-11.2\%), blood donors without caller tunes (from $19.7 \%-21.1 \%$ ), as well as nonblood donors without caller tunes (46.2\%-47.4\%). Results for the research models without free of cost have not been reported.

Compared with perceived usefulness, attitudes to using caller tunes for blood donation had the stronger effects on intention to use caller tunes for promoting blood donation (Table 9), with the model for nonblood donors without caller tunes having the largest effect $(55 \%)$, followed by that for blood donors with caller tunes $(39.2 \%)$.

Moreover, $39.2 \%$ of the variance in attitudes to caller tunes for blood donation was explained by perceived ease of use and perceived usefulness of caller tunes for promoting blood donation among blood donors with caller tunes. The greatest effect of perceived ease of use and perceived usefulness on variance in attitudes to using caller tunes for promoting blood donation (55\%) was seen among nonblood donors without caller tunes (Table 9). 
Figure 2. Path model for blood donors with caller tunes. *** $\mathrm{P}<.001$.

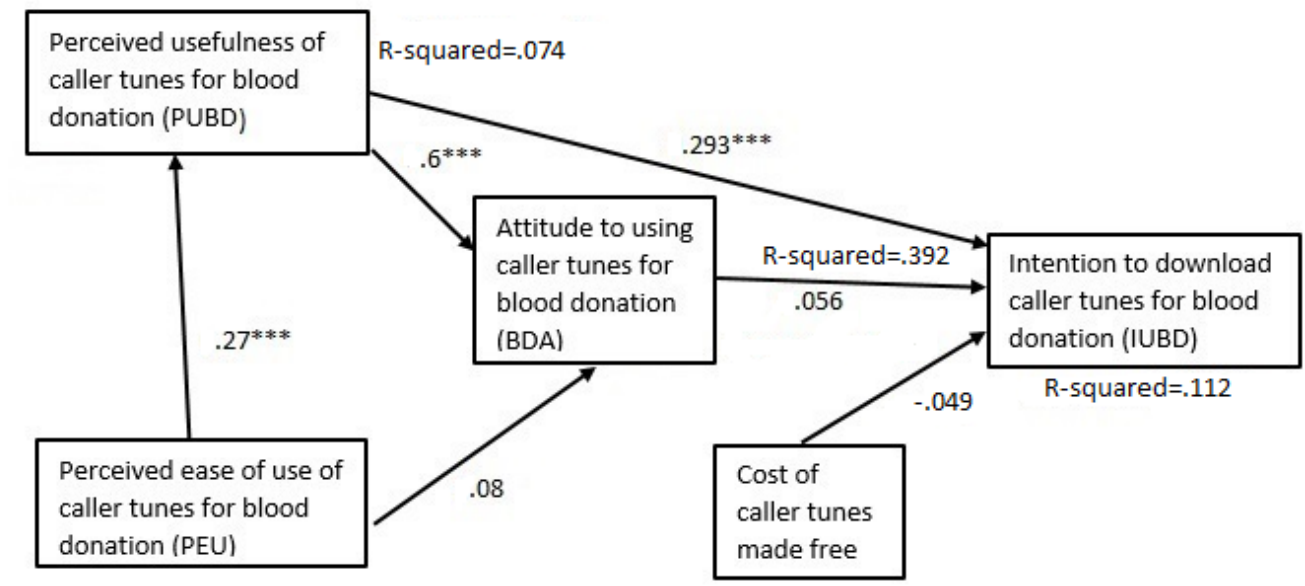

Figure 3. Path model for nonblood donors with caller tunes. *** $\mathrm{P}<.001$.

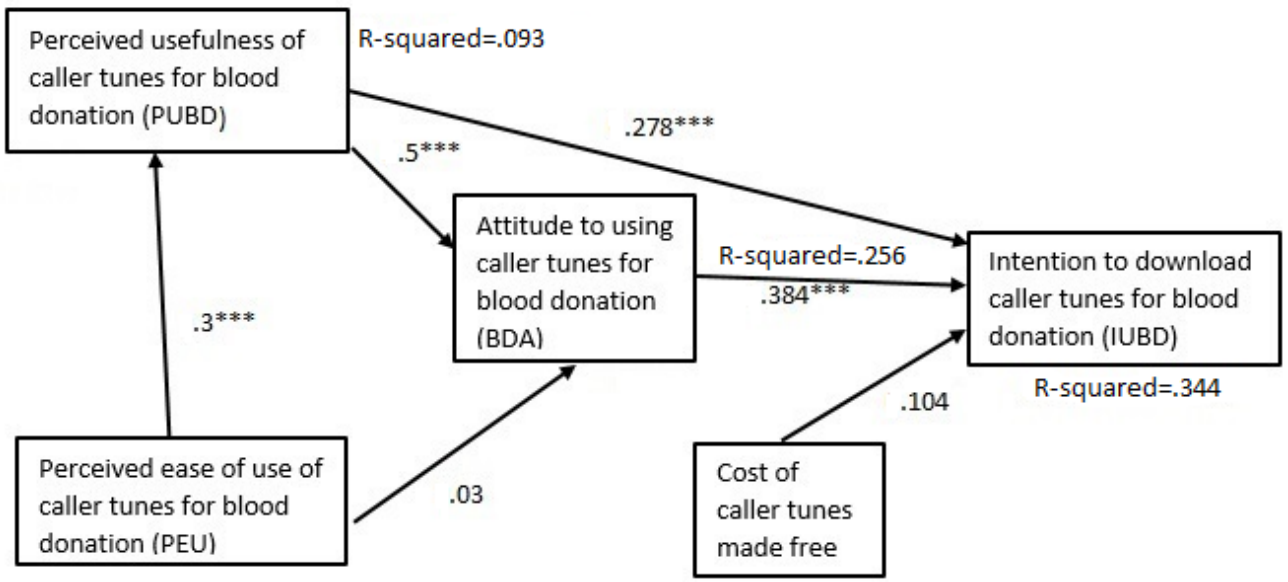

Figure 4. Path model for blood donors with no caller tunes. * $\mathrm{P}=.019 ; * * * \mathrm{P}<.001$.

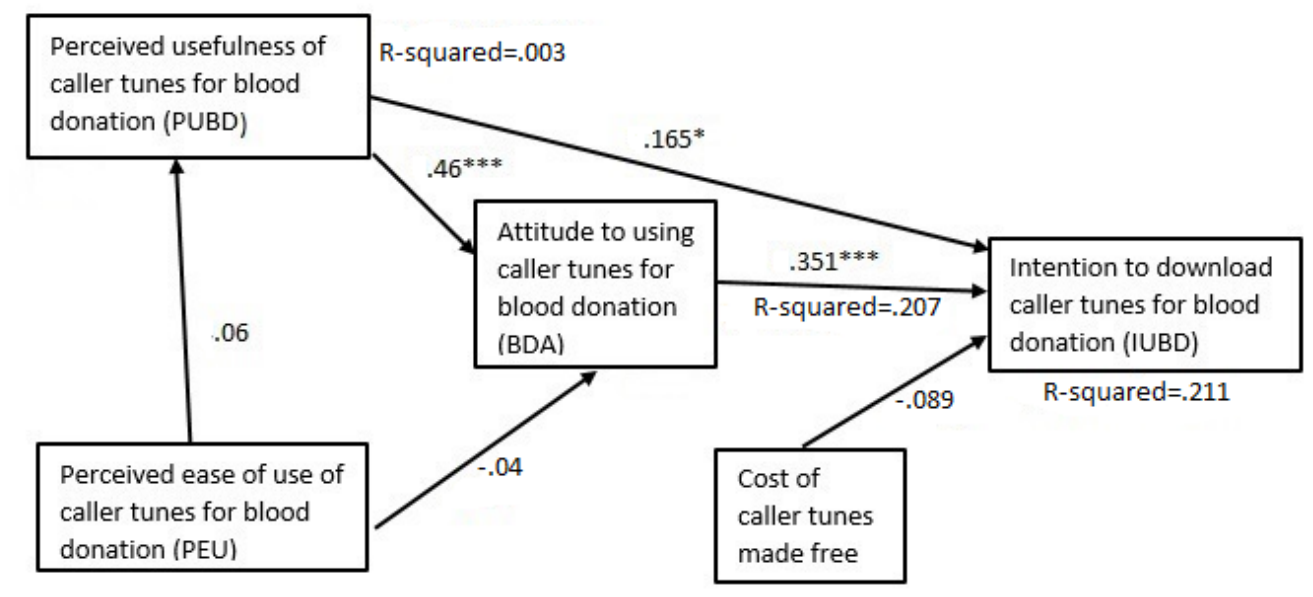


Figure 5. Path model for nonblood donors with no caller tunes. * $\mathrm{P}=.01$; *** $\mathrm{P}<.001$.

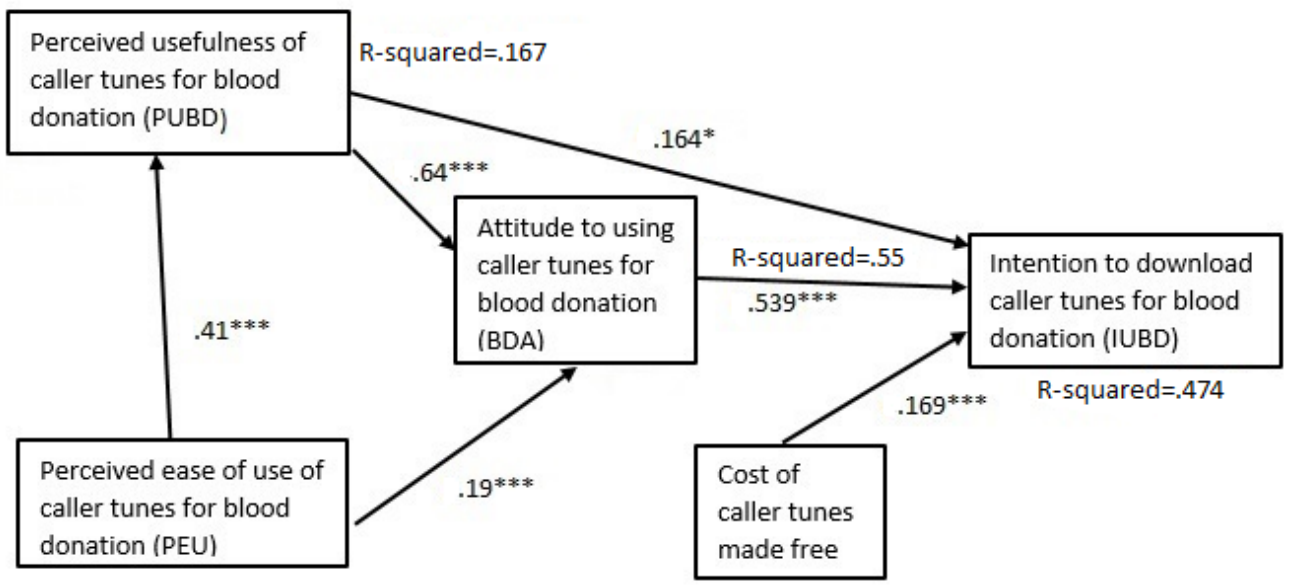

Table 9. Squared multiple correlations for blood or nonblood donors with or without caller tunes.

\begin{tabular}{lllll}
\hline Original & $\begin{array}{l}\text { Blood donors with } \\
\text { caller tunes }(\mathrm{n}=278)\end{array}$ & $\begin{array}{l}\text { Blood donors with no } \\
\text { caller tunes (n=208) }\end{array}$ & $\begin{array}{l}\text { Nonblood donors with } \\
\text { caller tunes (n=208) }\end{array}$ & $\begin{array}{l}\text { Nonblood donors with } \\
\text { no caller tunes }(\mathrm{n}=270)\end{array}$ \\
\hline Perceived usefulness for blood donation & 0.074 & 0.003 & 0.093 & 0.167 \\
$\begin{array}{l}\text { Attitudes to using caller tunes for blood dona- } \\
\text { tion }\end{array}$ & 0.392 & 0.207 & 0.256 & 0.55 \\
$\begin{array}{l}\text { Intention to use caller tunes for promoting } \\
\text { blood donation }\end{array}$ & 0.112 & 0.211 & 0.344 & 0.474 \\
\hline
\end{tabular}

\section{Discussion}

\section{Principal Findings}

Overall, our results provide empirical evidence for factors that could influence the intention of using mobile phone caller tunes for increasing blood donations. The findings mirror studies elsewhere that found significant relationship between perceived usefulness and attitudes to a health information [31,40,41] and intention to use technology $[31,33,42]$; and significant relationships between perceived ease of use and attitudes to technology [32,34-37] and perceived usefulness of the technology [38-40,42].

Despite considerable research having been conducted on the TAM, especially in the health care sector, our study is innovative for two reasons. It explores primary exogenous TAM variables - perceived ease of use and usefulness - in the context of the utility of mobile phone caller tunes for promoting blood donation. However, although blood donors or nonblood donors may believe that caller tunes are easy to download and could be useful for promoting blood donation, they may not have the resources or money to enable them to download the caller tunes. Our inclusion of free of cost as an additional variable yields useful information for determining whether caller tunes for blood donation should be free of cost to nonblood or blood donors.

With most of the fit indices within the recommended values, there is likelihood of good fit [64]. However, RMSEA value for blood donors with no caller tune was 0 , indicating exact model fit to the data [66]. This is a rare finding in surveys and might have research implication for the specified model for blood donors with no caller tunes. With RMSEA $P$ value of
.802 for this model (Table 7) based on $90 \% \mathrm{CI}$, our data appear to have good fit to the model. At samples sizes of at least 200 such as in this study, the use of $90 \%$ CI for estimating RMSEA provides comparable results with 95\% CI [67]. RMSEA values of 0.05 to 0.08 indicate close fit [68], thus making the model for nonblood donors with caller tunes the only one that appears not to fit the data. This model also had statistically significant RMSEA $(P=.046)$ and had NFI, IFI, Tucker Lewis index, and CFI values outside those recommended, suggesting that it may have implications for further research.

This study did not explore actual use of caller tunes for promoting blood donation because caller tunes for promoting blood donation are yet to be created. Nevertheless, our study is a necessary step for designing behavioral interventions using caller tunes to increase the number of first time donors and to encourage existing donors to donate regularly. It was surprising that perceived ease of use and perceived usefulness (Table 9) explained the greatest variance in attitudes to using caller tunes for blood donation among nonblood donors with no caller tunes (55\%). However, although perceived usefulness significantly impacted the attitudes to using caller tunes among all four groups of participants, perceived ease of use significantly impacted the attitudes of only nonblood donors with no caller tunes $(P=.04)$. This finding may be because nonblood donors with no caller tunes may be unaware of the ease with which they could get caller tunes onto their phones for promoting blood donation. Thus, should the caller tunes on blood donation be created, more efforts or promotion would be needed to positively influence the attitudes of nonblood donors without caller tunes. 
This finding suggests that efforts to promote uptake of caller tunes for blood donation should particularly target nonblood donors who do not already use caller tunes. Given that making caller tunes free to download was statistically significant in increasing intention to use caller tunes among only nonblood donors with no caller tunes, intervention designers would need to ensure that caller tunes for promoting blood donation become free. For example, affordability was found to be a statistically significant predictor of intention to use portable coagulometer devices for self-testing of the international normalized ratio among outpatients attending outpatient anticoagulation services [33].

Perceived ease of use, perceived usefulness, and attitudes are all important factors that could determine blood donors' and nonblood donors' intentions to use caller tunes to promote blood donation, should blood donation-themed caller tunes be designed. A caller to a mobile phone with a caller tune in Ghana may first hear "If you like this caller tune, press star to download," reflecting the ease with which caller tunes may be downloaded. The standardized coefficients for the impact of perceived usefulness on attitudes to using caller tunes for all four groups of participants were positive and statistically significant (Table 9). This finding suggests that perceived usefulness is a strong motivator to developing positive attitudes to using caller tunes, which could in turn increase intention to use caller tunes for blood donation. This finding provides practical implications for designing caller tune-based interventions for promoting blood donations. First, should caller tunes for blood donation become available, blood center staff may need to keep reminding both blood donors and nonblood donors about the usefulness of using caller tunes for promoting blood donation. Second, instead of the standard message "If you like this caller tune, press star to download," if feasible, perhaps mobile telecommunication companies may need to consider customizing such a message. For example, it could be "If you want to save lives with this caller tune on blood donation, press star to download."

A surprising finding of this study is that making caller tunes free to download appears to have significant positive effect on intention among only nonblood donors with no caller tunes. Conversely, it had negative effect on intention among blood donors, although the effects were nonsignificant. One reason might be that donors were already donating blood and those nondonors were already using caller tunes. Thus, free download did not have a significant impact on these types of participants. Another potential explanation for this finding may be that blood donors may be more willing to promote blood donation by paying the current cost of caller tunes (which is usually about 10 cents per month). For nonblood donors with no caller tunes, cost may be a factor in their current nonuse of caller tunes.

The findings of our study suggest that TAM has a high explanatory power for behavioral intention to use caller tunes-an information system-especially among nonblood donors (Table 9). This is because the variance in behavioral intention in our study was $34.4 \%$ for nonblood donors with caller tunes and $47.4 \%$ for nonblood donors with no caller tunes compared with those for blood donors with caller tunes (11.2.\%) and blood donors with no caller tunes $(21.1 \%)$.

\section{Conclusions}

This study is innovative because it applies the TAM to mobile phone caller tunes, a technology that is yet to be explored for promoting blood donation. The study also introduces an external factor-free of cost-and finds that it is particularly relevant for nonblood donors with no caller tunes. Our finding that making caller tunes free of cost could significantly increase intention of nonblood donors with no caller tunes to download them offers insight into the use of caller tunes for blood donation. To the best of our knowledge, this is the first study to explore the determinants of intention for downloading caller tunes to promote blood donation.

Thus, this research contributes to TAM in the context of mobile phone caller tunes. Our research models provide theoretical and practical implications for designing caller tunes for blood donation in Ghana and elsewhere. A major strength of our study is that it helps explain relevant variables that influence intentions for downloading caller tunes for those with or without caller tunes.

Our study contributes to information technology or information systems research in at least three ways. We applied TAM in a new context (ie, mobile phone caller tunes for blood donation), which is distinct from prior studies targeting health information systems. Our findings are consistent with those of many studies showing that perceived ease of use and perceived usefulness are significant predictors of behavioral intention [31,33,38,42]. Our study supports others that have showed significant positive relationship between cost and intention to use information technology $[33,44]$. However, it is important to note that free of cost is a significant factor particularly for those who do not already have the technology (in our case mobile phone caller tunes) and are also not currently adherent to the intended behavior (in our case blood donation). Measures of perceived ease of use were adapted from prior studies and differentiated for those who have or are without the technology under study. Scholars in Ghana and elsewhere could build on them for studying behavioral intention to use mobile phone caller tunes for promoting blood donation.

\section{Limitations}

This study has some limitations. Unlike mobile phone SMS text messages, mobile phone caller tunes for blood donation is relatively new. More research is needed to help generalize the findings in other populations. This is particularly relevant given that this study relied on a convenience sample that excluded participants who were absent at blood donation sites. In addition, we did not differentiate between different types of blood donors such as regular or paid donors. Future research may require a need to identify intention among different types of blood donors to download caller tunes for promoting blood donation. The study also lacks additional variables for explaining intentions for using caller tunes for blood donation. These factors could include social norms. Moreover, the construct for measuring behavioral intention was based on a single-item variable. A study of single-item variables [69] showed that such items are reliable for constructs that are unlikely to be misunderstood by respondents. Future research may need more items for measuring intentions. Furthermore, because our findings were obtained 
from cross-sectional data, longitudinal studies are needed to help predict intention to use caller tune for blood donation over time. This is because as people gain experience, beliefs or intentions could change.

\section{Acknowledgments}

The authors would like to thank Texas A\&M University Program to Enhance Scholarly and Creative Activities (PESCA) for funding the project. The authors would also like to thank Franklin Konadu Addo Agyeman, Joana Gyimah, and the National Blood Service Ghana for providing support with data collection.

The open access publishing fees for this article have been covered by the Texas A\&M University Open Access to Knowledge Fund (OAKFund), supported by the University Libraries and the Office of the Vice President for Research.

\section{Conflicts of Interest}

None declared.

\section{Multimedia Appendix 1}

Operationalization of constructs.

[PDF File (Adobe PDF File), 93KB-Multimedia Appendix 1]

\section{Multimedia Appendix 2}

Supplementary questionnaire focusing only on blood donation and caller tunes.

[PDF File (Adobe PDF File), 48KB-Multimedia Appendix 2]

\section{References}

1. Osaro E, Charles AT. The challenges of meeting the blood transfusion requirements in Sub-Saharan Africa: the need for the development of alternatives to allogenic blood. J Blood Med 2011;2:7-21 [FREE Full text] [doi: 10.2147/JBM.S17194] [Medline: 22287859]

2. Lund TC, Hume H, Allain JP, McCullough J, Dzik W. The blood supply in Sub-Saharan Africa: needs, challenges, and solutions. Transfus Apher Sci 2013 Dec;49(3):416-421. [doi: 10.1016/j.transci.2013.06.014] [Medline: 23871466]

3. World Health Organization. Blood safety and availability Fact sheet URL: http://www.who.int/en/news-room/fact-sheets/ detail/blood-safety-and-availability [accessed 2018-04-13] [WebCite Cache ID 6yeSxo64B]

4. Mwaba K, Keikelame MJ. Blood donation behaviour and beliefs among a sample of high school students in Mmabatho. Curationis 1995 Aug;18(3):2-3. [Medline: $\underline{\text { 8697521] }}$

5. Asamoah-Akuoko L, Hassall OW, Bates I, Ullum H. Blood donors' perceptions, motivators and deterrents in Sub-Saharan Africa-a scoping review of evidence. Br J Haematol Jun 2017;177(6):864-877. [Medline: 28542841]

6. Obi SN. Antenatal blood donation for pregnant Nigerian mothers: the husbands' perspective. J Obstet Gynaecol 2007 Jul;27(5):467-469. [doi: 10.1080/01443610701405986] [Medline: 17701791]

7. Salaudeen AG, Odeh E. Knowledge and behavior towards voluntary blood donation among students of a tertiary institution in Nigeria. Niger J Clin Pract 2011;14(3):303-307 [FREE Full text] [doi: 10.4103/1119-3077.86773] [Medline: 22037074]

8. Asamoah-Akuoko L, Hassall OW, Bates I, Adongo PB, Bygbjerg IC, Ullum H. Socio-demographic characteristics and attitudinal factors in first-time voluntary and family replacement blood donors in Southern Ghana. Vox Sang Sep 2016;111(1):120.

9. Dahourou H, Tapko JB, Kienou K, Nebie K, Sanou M. Recruitment of blood donors in Burkina Faso: how to avoid donations from family members? Biologicals 2010 Jan;38(1):39-42. [doi: 10.1016/j.biologicals.2009.10.017] [Medline: 20144550]

10. Sekongo YM, Yao D, Konate S, Kabore S, Dembele B, Kouamenan G, et al. Satisfaction survey of blood donors in national center for blood in Abidjan, Cote d'ivoire. Vox Sang 2011 Nov;101(1):51.

11. Appiah B, Bates I, Owusu-Ofori S, Dunn A. Culturally relevant communication interventions to promote voluntary blood donations in Ghana: an observational, interview-based study. Lancet 2013 Oct 20;382:8. [doi: 10.1016/S0140-6736(13)62169-8]

12. Odongo TJ, Sugut WK, Mwangi JW, Kimani DK, Nyamongo JA, Maikweki L, et al. Re-branding the Kenya National Blood Transfusion Service: a prospect for improving visibility. Transfusion 2009 Sep 01;49(3):254A.

13. Odongo T, Dahir A, Kinyota P. Kenya Nbts experience: a marketing communication approach to blood donor recruitment. Vox Sang 2011 Jul 01;101:123.

14. Diakhate L, Blavy G, Akue BA. Blood transfusion in Senegal: psychophysiologic study of blood donation. Bull Soc Pathol Exot Filiales Dec 1984;77(5):699-704. [Medline: $\underline{6525728}$ ]

15. Duboz P, Macia E, Cunéo B. Sociodemographic and attitudinal factors to blood donation in the urban population of Dakar, Senegal. Transfusion 2010 Dec;50(12):2713-2720. [doi: 10.1111/j.1537-2995.2010.02750.x] [Medline: 20561294] 
16. Agbovi K, Kolou M, Fétéké L, Haudrechy D, North M, Ségbéna A. [Knowledge, attitudes and practices about blood donation. A sociological study among the population of Lomé in Togo]. Transfus Clin Biol 2006 Oct;13(4):260-265. [doi: 10.1016/j.tracli.2006.06.002] [Medline: 16996292]

17. Wangendo J. Feasibility and acceptability of sms technology among blood donors in Nairobi. Vox Sang 2012 Jul 01;103(4):93-94.

18. Poushter J, Oates R. Pewglobal.: Pew Research Center; 2015 Apr 15. Cell phones in Africa: Communication lifeline texting most common activity, but mobile money popular in several countries URL: http://www.pewglobal.org/files/2015/04/ Pew-Research-Center-Africa-Cell-Phone-Report-FINAL-April-15-2015.pdf [accessed 2018-04-13] [WebCite Cache ID 6ui4JvRgY]

19. Aranda-Jan CB, Mohutsiwa-Dibe N, Loukanova S. Systematic review on what works, what does not work and why of implementation of mobile health (mHealth) projects in Africa. BMC Public Health 2014 Feb 21;14:188 [FREE Full text] [doi: 10.1186/1471-2458-14-188] [Medline: 24555733]

20. Ouhbi S, Fernández-Alemán JL, Toval A, Idri A, Pozo JR. Free blood donation mobile applications. J Med Syst 2015 May;39(5):52. [doi: 10.1007/s10916-015-0228-0] [Medline: 25732077]

21. Wangendo JN, Ochieng B, Oduor M. Feasibility and acceptability of sms technology among blood donors in Nairobi. Transfusion 2011 Sep 01;51:106A-107A.

22. Yoo W, Kim S, Hong Y, Chih M, Shah D, Gustafson D. Patient-clinician mobile communication: analyzing text messaging between adolescents with asthma and nurse case managers. Telemed J E Health 2015 Jan 01;21(1):62-69.

23. T-Mobile. Support.t-mobile. CallerTunes URL: https://support.t-mobile.com/docs/DOC-3277 [accessed 2018-04-13] [WebCite Cache ID 6wmuIKUcU]

24. Myles T. It Still Works. 2018. What Is the Difference Between Ringtones \& Ringback Tones? URL: https://itstillworks. com/difference-between-ringtones-ringback-tones-12284.html [accessed 2018-04-13] [WebCite Cache ID 6wmu8FPyl]

25. Vodafone Ghana. Vodafone. 2008. Caller Tunes URL: http://www.vodafone.com.gh/personal/plans/vas/callertunes [accessed 2018-04-13] [WebCite Cache ID 6wnGr23ID]

26. Owusu-Ofori S, Asenso-Mensah K, Boateng P, Sarkodie F, Allain J. Fostering repeat donations in Ghana. Biologicals 2010 Jan;38(1):47-52. [doi: 10.1016/j.biologicals.2009.10.021] [Medline: 20093042]

27. World Health Organization. WHO. 2014 Jun 13. World Blood Donor Day: Safe blood for saving mothers URL: http://www. who.int/campaigns/world-blood-donor-day/2014/en/ [accessed 2018-04-13] [WebCite Cache ID 6ui4g5jB3]

28. Holden RJ, Karsh BT. The technology acceptance model: its past and its future in health care. J Biomed Inform 2010 Feb;43(1):159-172 [FREE Full text] [doi: 10.1016/j.jbi.2009.07.002] [Medline: 19615467]

29. Lee Y, Kozar KA, Larsen KR. The technology acceptance model: past, present, and future. CAIS 2003 Dec 29;12(1):50 [FREE Full text]

30. Lai PC. The literature review of technology adoption models and theories for the novelty technology. JISTEM 2017 Apr;14(1):21-38. [doi: 10.4301/S1807-17752017000100002]

31. Hu PJ, Chau PY, Sheng OR, Tam KY. Examining the technology acceptance model using physician acceptance of telemedicine technology. J Manage Inform Syst 1999 Sep 01;16(2):91-112. [doi: 10.1080/07421222.1999.11518247]

32. Davis FD. Perceived usefulness, perceived ease of use, and user acceptance of information technology. MIS Q 1989 Sep 01;13(3):319-340 [FREE Full text]

33. Shah SG, Barnett J, Kuljis J, Hone K, Kaczmarski R. Factors determining patients' intentions to use point-of-care testing medical devices for self-monitoring: the case of international normalized ratio self-testing. Patient Prefer Adherence 2013;7:1-14 [FREE Full text] [doi: 10.2147/PPA.S38328] [Medline: 23300344]

34. Han S, Mustonen P, Seppänen M, Kallio M. Does fragmenting of working time and working space influence the acceptance of mobile technology. A case of Finnish physicians. TUCS Technical Reports 2005;657:-.

35. Davis FD. User acceptance of information technology: system characteristics, user perceptions and behavioral impacts. Int J Man Mach Stud 1993 Mar 01;38(3):475-487.

36. Chau PY. An empirical investigation on factors affecting the acceptance of CASE by systems developers. Inf Manage 1996 Sep -1;30(6):269-280.

37. Taylor S, Todd P. Understanding information technology usage: a test of competing models. Inform Syst Res 1995 Jun;6(2):144-176. [doi: 10.1287/isre.6.2.144]

38. Barker DJ, Van Schaik P, Simpson DS, Corbett WA. Evaluating a spoken dialogue system for recording clinical observations during an endoscopic examination. Med Inform Internet Med 2003 Jun;28(2):85-97. [Medline: 14692586]

39. Yi MY, Jackson JD, Park JS, Probst JC. Understanding information technology acceptance by individual professionals: toward an integrative view. Inf Manage 2006 Apr 30;43(3):350-363. [doi: 10.1016/j.im.2005.08.006]

40. Paré G, Sicotte C, Jacques H. The effects of creating psychological ownership on physicians' acceptance of clinical information systems. J Am Med Inform Assoc 2006;13(2):197-205 [FREE Full text] [doi: 10.1197/jamia.M1930] [Medline: 16357351]

41. Schaper L, Pervan G. ICT and OTs: a model of information and communication technology acceptance and utilisation by occupational therapists. Int J Med Inform 2007 Jun;76 Suppl 1:S212-S221. [doi: 10.1016/j.ijmedinf.2006.05.028] [Medline: $\underline{16828335]}$ 
42. Wu JH, Wang SC, Lin LM. Mobile computing acceptance factors in the healthcare industry: a structural equation model. Int J Med Inform 2007 Jan 31;76(1):66-77. [doi: 10.1016/j.ijmedinf.2006.06.006]

43. Moore GC, Benbasat I. Integrating diffusion of innovations theory of reasoned action models to predict utilization of information technology by end-users. In: Kautz K, Pries-Heje J, editors. Diffusion and Adoption of Information Technology. IFIP — The International Federation for Information Processing. Boston, MA: Springer; 1996:132-146.

44. Sun Y, Wang N, Guo X, Peng JZ. Understanding the acceptance of mobile health services: a comparison and integration of alternative models. J Electron Commer Re 2013 May 01;14(2):182-200.

45. Venkatesh V, Morris MG, Davis GB, Davis FD. User acceptance of information technology: toward a unified view. MIS Q 2003 Sep;27(3):425-478 [FREE Full text]

46. Rawstorne P, Jayasuriya R, Caputi P. Issues in predicting and explaining usage behaviors with the technology acceptance model and the theory of planned behavior when usage is mandatory. 2000 Dec 10 Presented at: The twenty first international conference on Information systems; 2000; Brisbane, Queensland, Australia p. 35-44 URL: https://dl.acm.org/citation. cfm?id=359721

47. Chen $\mathrm{CC}, \mathrm{Wu}$ J, Crandall RE. Obstacles to the adoption of radio frequency identification technology in the emergency rooms of hospitals. Int J Electron Healthc 2007;3(2):193-207. [doi: 10.1504/IJEH.2007.013100] [Medline: 18048269]

48. Venkatesh V, Davis FD. A theoretical extension of the technology acceptance model: four longitudinal field studies. Manage Sci 2000 Feb;46(2):186-204. [doi: 10.1287/mnsc.46.2.186.11926]

49. Park N, Roman R, Lee S, Chung JE. User acceptance of a digital library system in developing countries: an application of the Technology Acceptance Model. Int J Inform Manage 2009 Jun 1;29(3):196-209. [doi: 10.1016/j.ijinfomgt.2008.07.001]

50. Schepers J, Wetzels M. A meta-analysis of the technology acceptance model: investigating subjective norm and moderation effects. Inf Manage 2007 Jan 01;44(1):90-103. [doi: 10.1016/j.im.2006.10.007]

51. Legris P, Ingham J, Collerette P. Why do people use information technology? A critical review of the technology acceptance model. Inf Manage 2003 Jan 01;40(3):191-204. [doi: 10.1016/S0378-7206(01)00143-4]

52. Porter CE, Donthu N. Using the technology acceptance model to explain how attitudes determine Internet usage: The role of perceived access barriers and demographics. J Bus Res 2006 Sep 01;59(9):999-1007. [doi: 10.1016/j.jbusres.2006.06.003]

53. Aggelidis VP, Chatzoglou PD. Using a modified technology acceptance model in hospitals. Int J Med Inform 2009 Feb;78(2):115-126. [doi: 10.1016/j.ijmedinf.2008.06.006] [Medline: 18675583]

54. Chismar WG, Wiley-Patton S. Test of the technology acceptance model for the internet in pediatrics. Send to Proc AMIA Symp 2002:155-159. [Medline: 12463806]

55. Tung FC, Chang SC, Chou CM. An extension of trust and TAM model with IDT in the adoption of the electronic logistics information system in HIS in the medical industry. Int J Med Inform 2008 May;77(5):324-335. [doi: 10.1016/j.ijmedinf.2007.06.006] [Medline: 17644029]

56. Liang H, Xue Y, Byrd TA. PDA usage in healthcare professionals: testing an extended technology acceptance model. Int J Mob Commun 2003 Jan 01;1(4):372-389. [doi: 10.1504/IJMC.2003.003992]

57. Duyck P, Pynoo B, Devolder P, Voet T, Adang L, Vercruysse J. User acceptance of a picture archiving and communication system. Applying the unified theory of acceptance and use of technology in a radiological setting. Methods Inf Med 2008;47(2):149-156. [Medline: 18338086]

58. Kemper EA, Stringfield S, Teddlie C. Mixed methods sampling in social science research. In: Tashakkori A, Teddlie C, editors. Handbook of Mixed Methods in Social and Behavioral Research. Thousand Oaks, CA: Sage Publications; 2003:273-296.

59. Hoyle RH, Panther AT. Writing about structural equation models. In: Hoyle RH, editor. Structural Equation Modeling: Concepts, Issues, and Applications. Thousand Oaks, CA: Sage Publications; 1995:158-176.

60. Olsson U, Foss T, Troye S, Howell R. The performance of ML, GLS, and WLS estimation in structural equation modeling under conditions of misspecification and nonnormality. Struct Equ Modeling 2000 Oct 01;7(4):557-595.

61. Gillenson ML, Sherrell DL, Chen L. Enticing online consumers: an extended technology acceptance perspective. Inf Manage 2002 Sep 01;39(8):705-719. [doi: 10.1016/S0378-7206(01)00127-6]

62. van der Heijden H. Factors influencing the usage of websites: the case of a generic portal in The Netherlands. Inf Manage 2003 Jul 01;40(6):541-549. [doi: 10.1016/S0378-7206(02)00079-4]

63. Fornell C, Larcker DF. Evaluating structural equation models with unobservable variables and measurement error. J Mark Res 1981 Feb 01:39-50 [FREE Full text]

64. Schreiber JB, Nora A, Stage FK, Barlow EA, King J. Reporting structural equation modeling and confirmatory factor analysis results: a review. J Educ Res 2006 Jul 01;99(6):323-338. [doi: 10.3200/JOER.99.6.323-338]

65. Shin DH, Shin YJ, Choo H, Beom K. Smartphones as smart pedagogical tools: implications for smartphones as u-learning devices. Comput Hum Behav 2011 Nov 01;27(6):2207-2214. [doi: 10.1016/j.chb.2011.06.017]

66. Chen F, Curran PJ, Bollen KA, Kirby J, Paxton P. An empirical evaluation of the use of fixed cutoff points in RMSEA test statistic in structural equation models. Sociol Methods Res 2008 May 01;36(4):462-494. [Medline: 19756246]

67. Curran PJ, Bollen KA, Chen F, Paxton P, Kirby JB. Finite sampling properties of the point estimates and confidence intervals of the RMSEA. Sociol Methods Res 2003 Nov 01;32(2):208-252. [doi: 10.1177/0049124103256130] 
68. Schumacker RE, Lomax RG. A Beginner's Guide to Structural Equation Modeling. New York, NY: Routledge; Oct 12, 2012:107-143.

69. Wanous JP, Reichers AE, Hudy MJ. Overall job satisfaction: how good are single-item measures? J Appl Psychol 1997;82(2):247-252. [Medline: 9109282]

\author{
Abbreviations \\ ADR: adverse drug reaction \\ AVE: average variance extracted \\ BDA: refers to attitudes to using caller tunes for blood donation \\ CFDBD1: implies free of cost \\ CFI: comparative fit index \\ IFI: incremental fit index \\ IUBD: intention to use caller tunes for promoting blood donation \\ mHealth: mobile health \\ NFI: normed fit index \\ PEU: perceived ease of use caller tunes for promoting blood donation \\ PUBBD: perceived usefulness for blood donation \\ RMSEA: root mean square error of approximation \\ TAM: technology acceptance model \\ WHO: World Health Organization
}

\author{
Edited by $G$ Eysenbach; submitted 31.12.17; peer-reviewed by S Shah, R Pankomera; comments to author 23.01.18; revised version \\ received 14.02.18; accepted 23.02.18; published 04.05.18 \\ Please cite as: \\ Appiah B, Burdine JN, Aftab A, Asamoah-Akuoko L, Anum DA, Kretchy IA, Samman EW, Appiah PB, Bates I \\ Determinants of Intention to Use Mobile Phone Caller Tunes to Promote Voluntary Blood Donation: Cross-Sectional Study \\ JMIR Mhealth Uhealth 2018;6(5):e117 \\ URL: http://mhealth.jmir.org/2018/5/e117/ \\ doi: $10.2196 /$ mhealth. 9752 \\ PMID: 29728343
}

CBernard Appiah, James N Burdine, Ammar Aftab, Lucy Asamoah-Akuoko, David A Anum, Irene A Kretchy, Elfreda W Samman, Patience B Appiah, Imelda Bates. Originally published in JMIR Mhealth and Uhealth (http://mhealth.jmir.org), 04.05.2018. This is an open-access article distributed under the terms of the Creative Commons Attribution License (https://creativecommons.org/licenses/by/4.0/), which permits unrestricted use, distribution, and reproduction in any medium, provided the original work, first published in JMIR mhealth and uhealth, is properly cited. The complete bibliographic information, a link to the original publication on http://mhealth.jmir.org/, as well as this copyright and license information must be included. 